\title{
MAGNETIC RESONANCE SPECTROSCOPY IN CHILDREN WITH NON-ACUTE NEUROLOGICAL ILLNESS
}

\author{
Amarnath Chellathurai ${ }^{1}$, Sukumar Ramaswami2, Sebastian Antony Xavier ${ }^{3}$, A Thangalakshmi4, Sivakumar Kannappan ${ }^{5}$, \\ Balaji Ayyamperumal ${ }^{6}$
}

1 Professor, Department of Radiodiagnosis, Stanley Medical College, Chennai, Tamilnadu. 2Professor, Department of Radiodiagnosis, Stanley Medical College, Chennai, Tamilnadu. 3Junior Resident, Department of Radiodiagnosis, Stanley Medical College, Chennai, Tamilnadu. ${ }^{4}$ Senior Resident, Department of Radiodiagnosis, Stanley Medical College, Chennai, Tamilnadu. ${ }^{5}$ Senior Resident, Department of Radiodiagnosis, Stanley Medical College, Chennai, Tamilnadu. ${ }^{6}$ Senior Resident, Department of Radiodiagnosis, Stanley Medical College, Chennai, Tamilnadu.

\section{BACKGROUND}

ABSTRACT

The causes of non-acute neurological illness presenting as developmental delay and regression of attained milestones are frequently unknown, and clinicians and families can be frustrated by the lack of neuroimaging correlation especially when considering therapeutic options and long-term prognosis.

The goal of our study is to determine if proton MR spectroscopy can depict abnormalities in patients with non-acute neurological illness with special reference to children with developmental delay and regression of attained milestones.

\section{MATERIALS AND METHODS}

This is a retrospective descriptive study, where imaging of 615 children with non-acute neurological illness were included. Among those, 424 children's MR spectroscopy whose preliminary MRI showed predominantly normal or non-specific findings were analysed by two radiologists. MR spectroscopy was performed as per institutional protocol with multivoxel grid placed in bilateral subcortical white matter in the frontal and parieto-occipital regions, bilateral thalami and basal ganglia. The diagnosis was confirmed with biochemical, pathological, genetic studies and enzyme analysis.

\section{RESULTS}

Spectra of 198 children showed no specific findings in MRS to arrive at a specific diagnosis. Spectra of 153 children showed mild decrease in NAA and mild decrease in NAA/Cr ratio, which indicates neuronal depletion and is non-specific with no biochemical/genetic abnormality and were diagnosed as idiopathic developmental delay. 58 children were significantly different with smaller NAA peaks and decreased NAA/ Cr ratios were diagnosed as Neuronal Ceroid Lipofuscinosis, 3 children with elevated lipid peak at 0.9 and 1.3 ppm were diagnosed as Sjogren-Larsson Syndrome, 3 children with absent creatine peak were diagnosed as Cerebral creatine deficiency, 3 children with decreased NAA peak and mild elevated Cho/ Cr ratio were diagnosed as GM1 gangliosidosis. One child presented with non-specific white matter hyperintensity in MRI and elevated peak at 2 ppm similar to that of NAA was diagnosed as Salla disease. One child with broad based lipid peak at 0.9 - 1.3 ppm and was diagnosed as disorder of beta-oxidation of fatty acid. Two children showed single peak noted at $3.5 \mathrm{ppm}$ denoting glycine and was diagnosed as hyperglycinaemia. Phenylalanine peaks were noted in two children at $7.36 \mathrm{ppm}$ and were diagnosed as Phenylketonuria.

\section{CONCLUSION}

MRS is the useful surrogate study to arrive at a diagnosis in children with non-acute neurological illness presenting as delayed development children and regression of attained milestones.

\section{KEY WORDS}

NAA- N-Acetyl Aspartic Acid, MI- Myoinositol, MRS- MR Spectroscopy, SLS- Sjogren-Larsson Syndrome, NCL- Neuronal Ceroid Lipofuscinosis, SD- Salla Disease, Cho- Choline, Creatine- Cr.

HOW TO CITE THIS ARTICLE: Chellathurai A, Ramaswami S, Xavier SA, et al. Magnetic resonance spectroscopy in children with non-acute neurological illness. J. Evolution Med. Dent. Sci. 2018;7(20):2481-2486, DOI: 10.14260/jemds/2018/558

\section{BACKGROUND}

MR imaging plays an important role in comprehensive evaluation of children with non-acute neurological illness as many specific aetiologic and pathophysiologic conditions can

'Financial or Other Competing Interest': None.

Submission 08-04-2018, Peer Review 01-05-2018,

Acceptance 08-05-2018, Published 14-05-2018.

Corresponding Author:

Sukumar Ramaswami,

Professor,

Department of Radiodiagnosis,

Stanley Medical College,

Chennai-1, Tamilnadu.

E-mail: drrsukumar@gmail.com

DOI: $10.14260 /$ jemds/2018/558 be detected.1-4 Children with mild neurodevelopmental delay frequently have normal findings in conventional MR Brain imaging examinations,5,7 where MR spectroscopy (MRS), a non-invasive technique by which metabolites in the brain are measured and information about enzyme related disorders is obtained can be used. Several investigators ${ }^{2-6}$ have used MRS to evaluate changes in cerebral metabolism during normal brain maturation and white matter myelination. MRS also has proved useful for assessment of developmental delay; neurodegenerative, inflammatory, metabolic and neuropsychiatric disorders; phakomatosis, hypoxic-ischaemic brain injury and epilepsy. ${ }^{7-12}$

Changes in choline (Cho) levels in children with developmental delay have been attributed to the availability of precursor molecules needed for myelination.13 Normally, 
the Cho/creatine $(\mathrm{Cr}$ ) ratio declines rapidly in the first few months of life owing to accelerated myelination, which incorporates Cho into macromolecules associated with myelin. ${ }^{14}$ As myelination proceeds normally, there is a rise in $\mathrm{N}$-acetyl aspartate (NAA) levels, which may correspond to dendritic proliferation or increased synaptic density.13,15,16

Conditions in children that lead to neuronal injury, neuronal loss or poor functional outcome have been associated with decreased NAA levels. ${ }^{15-17}$ NAA is found only within mitochondria in neurons and hence is considered a neuronal marker. Variations in the NAA/ $\mathrm{Cr}$ and $\mathrm{Cho} / \mathrm{Cr}$ ratios in these children may reflect underlying abnormalities of myelination or hypomyelination ${ }^{13,15}$ and diagnosing the aetiology for neuronal derangements.

The aim of our study is to determine if proton MR spectroscopy can depict abnormalities in patients with nonacute neurological illness with special reference to children with developmental delay and regression of attained milestones.

\section{MATERIALS AND METHODS}

This is a retrospective descriptive study of 610 children of age less than 15 years with developmental delay or with regression of attained milestones who were referred to our department from January 2014 to December 2017. Children with developmental delay and regression of attained milestones were included in the study. The children included in our study were aged upto ten years. Majority of the children aged between three and five and the mean age group was 4.2 . Among 610 children, 320 were male and 290 were female and MR spectroscopy study of 424 children with normal or non-specific MRI finding was analysed. Children with preliminary MRI showing focal brain lesions, trauma, brain and meningeal infections were excluded.

All children in our study group underwent complete medical, neurological and psychiatric evaluation. Majority of the children with non-acute neurological illness presented as developmental delay. The criteria to say developmental delay is absence of one or more milestones in terms of social smile, head control and other motor skills, behavioural development or learning. ${ }^{18}$ The clinical diagnosis of developmental delay was made by a paediatric neurologist. Children with clinically diagnosed developmental delay were referred for brain MR imaging to exclude a structural cause.

All participants were studied with a 1.5-T whole-body MR imager (Siemens Magnetom Aera, Germany) equipped with high-performance gradients using a manufacturer-supplied head coil. Routine sequences performed in all children were sagittal T1-weighted (608/17/1 [TR/TE/excitations]), axial fast spin-echo T2-weighted (4450/98/1), axial fast fluidattenuated inversion recovery (FLAIR) (90000/90/1, TI 2.2 seconds) and axial T1-weighted (500/14/1). In general, all axial sequences used $5 \mathrm{~mm}$ thickness with intersection gap of $3 \mathrm{~mm}$, a $305 \times 448$ matrix, the same imaging angle along the orbitomeatal line and a $200 \mathrm{~mm}$ field of view. Coronal fast FLAIR (10, 002/172/1, TI 2.2 seconds) and coronal spoiled gradient recalled acquisition in the steady state (SPGR) T1weighted volumetric $\left(17 / 5 / 1\right.$, flip angle $\left.15^{\circ}\right)$ sequences were obtained in all children.

In all patients, proton MR spectroscopy was performed by using chemical shift imaging (CSI) sequence (2000/144 and 135/35 [TR/TE]). Multivoxel grid was placed in bilateral subcortical white matter in the frontal and parieto-occipital regions, bilateral thalami and basal ganglia. Typical acquisition time per spectral acquisition was $3 \mathrm{mts} 10 \mathrm{~s}$. The spectra were assessed independently by two experienced Radiologists. Concordance between their findings was taken as a positive indicator that the spectrum was diagnostic for the pathology under consideration.

NAA reduction more than $25 \%$ on comparing with age matched controls was considered as significant (Moderate reduction in NAA). Absolute concentrations of brain metabolites was taken as reference for various age groups (Table 1). ${ }^{19-20}$

\begin{tabular}{|c|c|c|c|c|}
\hline Group & NAA & Cr & Cho & mI \\
\hline$<42 \mathrm{GA}$ & $3.9 \pm 1.6$ & $6.33 \pm 0.32$ & $2.41 \pm 0.11$ & $10.1 \pm 1.1$ \\
\hline $42-60 \mathrm{GA}$ & $7.03 \pm 0.41$ & $7.28 \pm 0.28$ & $2.23 \pm 0.06$ & $8.52 \pm 0.92$ \\
\hline$<2 \mathrm{pn}$ & $5.52 \pm 0.64$ & $6.74 \pm 0.63$ & $2.53 \pm 0.12$ & $12.4 \pm 1.4$ \\
\hline $2-10 \mathrm{pn}$ & $5.89 \pm 0.21$ & $6.56 \pm 0.44$ & $2.16 \pm 0.09$ & $7.69 \pm 0.62$ \\
\hline Adult & $8.89 \pm 0.17$ & $7.47 \pm 0.12$ & $1.32 \pm 0.07$ & $6.56 \pm 0.43$ \\
\hline Table 1. Absolute Concentrations of Brain Metabolites for \\
various Age Groups \\
\hline
\end{tabular}

Pn- postnatal, GA- gestational age, NAA- N-acetyl aspartic acid, mI- myoinositol, Cr- creatine, Cho- choline.

\section{RESULTS}

Among 424 children reviewed, 351 children were designated as idiopathic developmental delay since the spectra of 198 children were normal/ near normal (46.8\%) and spectra of 153 (36\%) children showed mild decreased NAA, mild decreased NAA/ Cr ratio with no other specific findings in MRS to arrive at a specific diagnosis. Abnormal spectral changes were seen in 73 children (17.2\%) (Table 2).

58 children with neuronal ceroid lipofuscinosis showed much smaller NAA peaks and decreased values of the NAA/Cr ratios and elevated $\mathrm{mI}$ peak in 27 patients with biochemical genetic analysis. After excluding other causes, they were diagnosed as neuronal ceroid lipofuscinosis and confirmed with skin biopsy. Many of the patients show cerebral, cerebellar atrophy and subtle white matter changes. MRI brain images of three children with non-specific bilateral deep white matter hyperintensity with sparing of subcortical U-fibres and elevated lipid peak at 0.9 and $1.3 \mathrm{ppm}$ who also had a history of ichthyosis were diagnosed to have SjogrenLarsson syndrome. Diagnosis was confirmed with enzyme analysis. Spectra of three children with normal MRI images showed absent creatine peak, diagnosed as cerebral creatine deficiency syndrome and confirmed with biochemical analysis.

Three children with GM1 Gangliosidosis showed decreased NAA peak and decreased NAA/ $\mathrm{Cr}$ ratio and elevated Cho/ $\mathrm{Cr}$ ratio. One child presented with non-specific white matter changes in MRI and elevated peak at $2 \mathrm{ppm}$ similar to that of NAA was diagnosed as Salla disease. On further evaluation, there is elevated total and free sialic acid in urine and fibroblasts, confirmed by molecular analysis of the SLC17A5 gene. 


\begin{tabular}{|c|c|c|c|c|}
\hline No. & Diagnosis & MR Spectroscopy & \begin{tabular}{|c|} 
No. of \\
Children \\
\end{tabular} & $\%$ \\
\hline 1 & $\begin{array}{l}\text { Neuronal ceroid } \\
\text { lipofuscinosis }\end{array}$ & $\begin{array}{c}\downarrow \mathrm{NAA}, \downarrow \mathrm{NAA} / \mathrm{Cr} \\
\text { ratio, } \uparrow \mathrm{mI} \\
\uparrow \mathrm{mI} / \mathrm{Cr} \\
\end{array}$ & 58 & 13.7 \\
\hline 2 & $\begin{array}{l}\text { Sjogren-Larsson } \\
\text { syndrome }\end{array}$ & $\uparrow$ Lipid peak & 03 & 0.7 \\
\hline 3 & $\begin{array}{c}\text { Idiopathic } \\
\text { developmental } \\
\text { delay }\end{array}$ & $\begin{array}{c}\text { Normal spectrum } \\
\text { OR mild } \downarrow \text { NAA, } \\
\text { Mild } \downarrow \text { NAA/Cr ratio }\end{array}$ & 351 & 82.7 \\
\hline 4 & Phenylketonuria & $\begin{array}{c}\text { Elevated peak at } \\
7.36 \mathrm{ppm}\end{array}$ & 02 & 0.4 \\
\hline 5 & $\begin{array}{c}\text { Non-Ketotic } \\
\text { Hyperglycinaemia }\end{array}$ & $\begin{array}{c}\text { Elevated peak at } 3.5 \\
\text { ppm }\end{array}$ & 02 & 0.4 \\
\hline 6 & $\begin{array}{l}\text { Disorder of Beta } \\
\text { oxidation of fatty } \\
\text { acid }\end{array}$ & $\begin{array}{c}\text { Broad based lipid } \\
\text { peak at } 0.9-1.3 \mathrm{ppm}\end{array}$ & 01 & 0.2 \\
\hline 7 & $\begin{array}{c}\text { Cerebral creatine } \\
\text { deficiency }\end{array}$ & Absent $\mathrm{Cr}$ peak & 03 & 0.7 \\
\hline 8 & GM1 gangliosidosis & \begin{tabular}{|c|}
$\downarrow \downarrow \mathrm{NAA}, \downarrow \mathrm{NAA} / \mathrm{Cr}$ \\
ratio, $\uparrow \mathrm{Cho} / \mathrm{Cr}$ ratio
\end{tabular} & 03 & 0.7 \\
\hline 9 & Salla disease & $\begin{array}{c}\text { Elevated peak at } \\
\text { 2ppm (NAS) }\end{array}$ & 01 & 0.2 \\
\hline & Total & & 424 & \\
\hline
\end{tabular}

\section{Abbreviation}

NAS- $\mathrm{N}$-acetyl sialic acid, NAA- $\mathrm{N}$-acetyl aspartic acid, $\mathrm{Cr}$ Creatine, mI- Myoinositol, Cho/ Cr ratio.

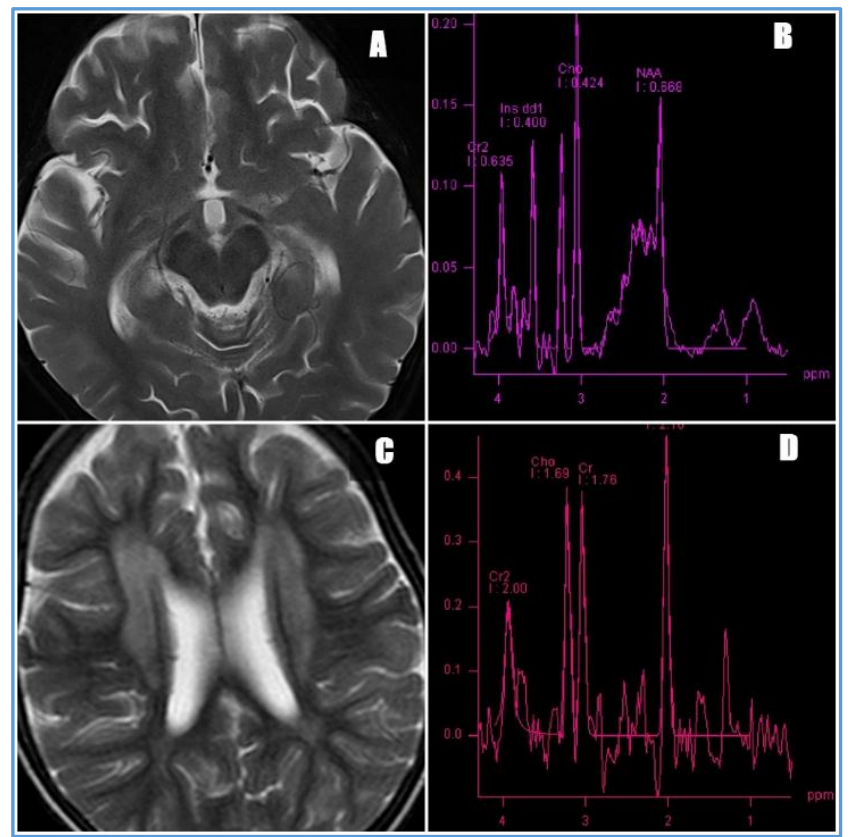

Figure 1. T2 Weighted MRI of a patient with Neuronal Ceroid Lipofuscinosis showing Normal Findings (A). MR Spectrum of the same Patient shows decreased NAA, decreased NAA/Cr ratio, Elevated Peak at 3.5 ppm (mI) and Increased $\mathrm{mI} / \mathrm{Cr}$ ratio (B). T2 weighted MRI of a patient with Sjogren-Larsson Syndrome showing High

Signal Areas in the Periventricular Region (C). MR Spectrum of the same patient demonstrates Elevated Lipid Peak (D).

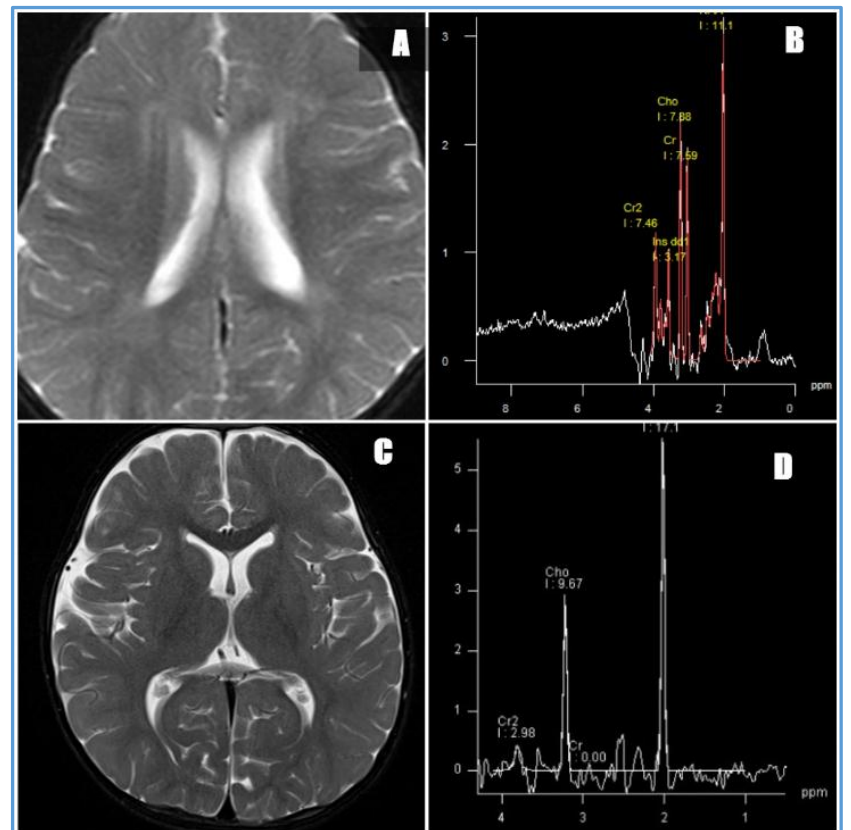

Figure 2. T2 Weighted MRI of a patient with Phenylketonuria showing Normal Findings (A). MR Spectrum of the same patient shows Elevated Peak at 7.36 ppm (B).T2 weighted MRI of a patient with Cerebral Creatine Deficiency showing Normal Findings (C). MR Spectrum of the same patient demonstrates Absent Creatine Peak (D).

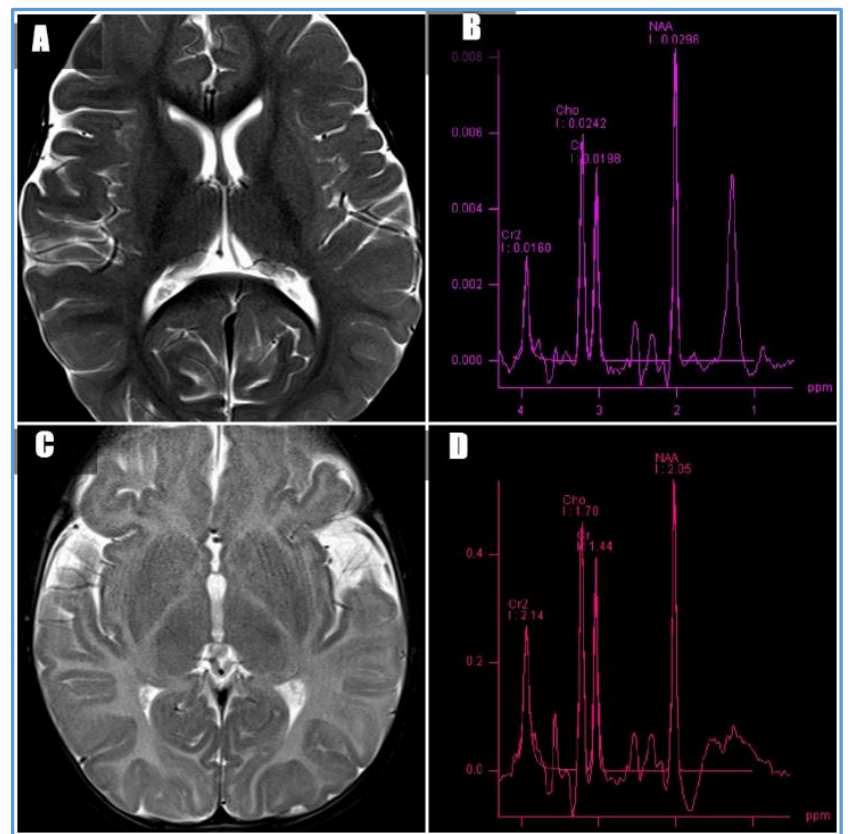

Figure 3. T2 Weighted MRI of a patient with BetaOxidation of Fatty Acid Disorder showing Normal Findings (A). MR Spectrum of the same patient shows Broad-Based Lipid Peak at 0.9 - 1.3 ppm (B). T2-Weighted MRI of a patient with Non-Ketotic Hyperglycinaemia showing Normal Findings (C). MR Spectrum of the same patient demonstrated Elevated Peak at 3.5 ppm which was assigned to Glycine (D). 


\section{DISCUSSION}

The lack of specific neuroimaging findings shall place neurologists in a dilemma with respect to decisions on further management protocols in patients with developmental delay and regression of attained milestones.

The clinical diagnosis of developmental delay is agedependent. Previously, serial MR imaging examinations were needed to differentiate arrested myelination from slow but progressive development disorders. In our study with MR spectroscopy, we were able to get a definite diagnostic clue for diseases like cerebral creatine deficiency, Salla disease and Sjogren-Larsson Syndrome. In other children included in the study, MRS showed decreased NAA and decreased $\mathrm{NAA} / \mathrm{Cr}$ ratio, though a common finding based on biochemical study/ enzyme analysis/ genetic correlation, they were diagnosed as NCL/ GM1 gangliosidosis/idiopathic developmental delay.

Altinok et $\mathrm{al}^{21}$ reported MRI findings of three siblings with diagnosis of Sjogren-Larsson syndrome confirmed by enzyme analysis. MRS directed to periventricular lesions revealed an abnormally high peak at the lipid range and decreased peak of NAA. A decreased NAA is an indicator of neuronal and axonal damage or dysfunction. It has been reported that the increased relative concentration of lipids corresponds precisely to the high signal areas observed on T2-weighted MRI.22-25 Our study also showed similar MRS findings in 3 children.

Neuronal ceroid lipofuscinosis is a devastating neurodegenerative storage disease caused by palmitoylprotein thioesterase 1 deficiency, which impairs degradation of palmitoylated proteins (constituents of ceroid) by lysosomal hydrolases. ${ }^{26}$ In our study group of 58 children with NCL, MRS showed much smaller NAA peaks and decreased values of the NAA/ $\mathrm{Cr}$ ratios. Increased myoinositol (mI), increased $\mathrm{mI} / \mathrm{Cr}$ ratio is noted in advanced NCL. ${ }^{27}$ Mild-to-moderate cerebral and cerebellar atrophy with periventricular T2/ FLAIR hyperintensities were also seen.

Similar spectra were seen in GM1 gangliosidosis, which is a lysosomal storage disease with b-galactosidase deficiency resulting in accumulation of GM1 ganglioside, oligosaccharides and keratan sulphate in the central nervous system, skeleton and vertebra. Three spectra were with decreased NAA peak and mild elevated Cho/ $\mathrm{Cr}$ ratio diagnosed as GM1 gangliosidosis by enzyme analysis. ${ }^{28}$

In our study three children showed marked reduction of cerebral creatine in MRS, which is highly indicative of primary cerebral creatine deficiency syndrome (CCDS). Creatine and phosphocreatine play an important role in the storage and transmission of phosphate-bound energy. ${ }^{29}$ Several patients with an almost invisible total creatine $(\mathrm{tCr})$ signal in the MRS have been described, explainable by inborn errors found in three steps of the creatine metabolic pathway. ${ }^{30}$ Phosphocreatine and creatine metabolism is stable and normal. If creatine levels were low due to a synthesis defect, creatinine would also be low. ${ }^{31}$ The first two errors appear in creatine biosynthesis as autosomal recessive deficiencies of arginine-glycine amidinotransferase (AGAT) and guanidinoacetate methyltransferase (GAMT). ${ }^{29}$ The third error is of creatine homeostasis, in which there is a mutation in the solute carrier family 6 member 8 (SLC6A8) gene mapped to Xq28, causing an X-linked creatine transporter deficiency syndrome.29 SLC6A8 encodes for cellular transporter CT1/ SLC6A8, which is responsible for creatine uptake in the central nervous system. ${ }^{29}$ With GAMT and AGAT deficiency patients, brain creatine can approach normal levels with creatine supplementation. In some instances for patients with GAMT deficiency, MRS can illustrate an elevation of guanidinoacetic acid (GAA) at 3.8 ppm. ${ }^{30}$ Primary screening of CCDS is by measuring creatine, creatine:creatinine ratio and guanidinoacetic acid in urine or blood or performing metabolite analysis. MRS can be used to document response to treatment of AGAT and GAMT deficiency. 32

In our study group one infant with developmental delay presented with non-specific white matter hyperintensity in brain. MRI images and MRS showed elevated peak at 2 ppm. In infantile age group the NAA peak would normally be smaller than choline peak and if any tall peak is seen at 2 ppm. Biochemical analysis of urine and fibroblast analysis for $\mathrm{N}$-acetyl sialic acid aid the diagnosis of Salla disease, further confirmed with molecular analysis.

Non-ketotic hyperglycinaemia (NKH) is an autosomal recessive disorder caused by a deficient glycine cleavage system and generally results in elevated glycine levels in urine, blood and cerebrospinal fluid (CSF). Such increases are harmless in blood, but can cause extensive neuronal damage in neonatal brain via $\mathrm{N}$-methyl-D-aspartate glutamate receptor-mediated excitotoxicity.33,34 Three reports describing the application of proton magnetic resonance spectroscopy (MRS) to NKH stating that long echo-time MRS detected a prominent peak at $3.5 \mathrm{ppm}$, which was assigned to glycine. ${ }^{35}$ In our study also, single peak noted at $3.5 \mathrm{ppm}$ denoting glycine was observed in two patients.

In our study two patients had peak at $7.36 \mathrm{ppm}$ and the parallel plasma concentrations were correspondingly correlated to elevated phenylalanine. Phenylketonuria (PKU) is an inborn error of amino acid metabolism, resulting from deficiency of hepatic phenylalanine hydroxylase. This deficiency results in impaired hydroxylation of phenylalanine (Phe) to tyrosine (Tyr), manifested as elevated plasma phenylalanine concentrations and low-to-normal plasma Tyr concentrations. Möller et $\mathrm{al}^{36}$ showed that in nine PKU patients, brain phenylalanine concentrations (determined by magnetic resonance spectroscopy) were positively associated with plasma phenylalanine concentrations.

Our study demonstrated broad-based lipid peak at 0.9 - 1.3 ppm in one patient without any changes in the brain in conventional MRI and was diagnosed as disorder of beta oxidation of fatty acid. Various in-vivo and in-vitro MRS studies have showed that lipid peak obtained in disorder of beta oxidation of fatty acid is predominantly polyunsaturated fatty acids, which are primarily constituents of mitochondrial membrane. 37

In our study, out of 356 idiopathic developmental delay 158 children's (44.4\%) spectra showed mild decrease in NAA and decrease in NAA/ $\mathrm{Cr}$ ratio suggestive of non-specific neuronal loss. Another 198 children showed normal spectrum. Filippi et al and Martin et al, ${ }^{2}$ Hashimoto et al reported a decreased NAA/ Cho ratio, but similar NAA/ $\mathrm{Cr}$ and Cho/ $\mathrm{Cr}$ ratios in a group of 28 mentally retarded children measured in a single voxel containing GM and WM leading to the conclusion that NAA is decreased. Martin et al 38 reported absence of NAA in the brain of a 3-year-old child 
with neurodevelopmental retardation and questioned NAA to be a neuronal marker. However, no cases with absent NAA was ascertained in our study.

There is no control group of normal children used in the study. Instead, we used references from other studies of absolute concentrations of brain metabolites for various age groups (Table 1). Developmental delay children are not further clinically classified as mild, moderate or severe in our study.

\section{CONCLUSION}

In children upto 15 years, clinically presenting as developmental delay and regression of attained milestones, with normal/ non-specific conventional MRI findings, MR spectroscopy provides additional information and can be used as a routine sequence.

\section{REFERENCES}

[1] Martin E, Keller M, Ritter S, et al. Contribution of proton magnetic resonance spectroscopy to the evaluation of children with unexplained developmental delay. Pediatr Res 2005;58(4):754-60.

[2] Filippi CG, Ulug AM, Deck MD, et al. Developmental delay in children: assessment with proton $\mathrm{MR}$ spectroscopy. Am J Neuroradiol 2002;23(5):882-8.

[3] Angelie E, Bonmartin A, Boudraa A, et al. Regional differences and metabolic changes in normal aging of the human brain: proton MR spectroscopic imaging study. Am J Neuroradiol 2001;22(1):119-27.

[4] Hashimoto T, Tayama M, Miyazaki $M$, et al. Developmental brain changes investigated with proton magnetic resonance spectroscopy. Dev Med Child Neurol 1995;37(5):398-405.

[5] Pouwels PJ, Brockmann K, Kruse B, et al. Regional age dependence of human brain metabolites from infancy to adulthood as detected by quantitative localized proton MRS. Pediatr Res 1999;46(4):474-85.

[6] Charles HC, Lazeyras F, Krishnan KR, et al. Proton spectroscopy of human brain: effects of age and sex. Prog Neuropsychopharmacol Biol Psychiatry 1994;18(6):995-1004.

[7] van der Voorn JP, Pouwels PJ, Hart AA, et al. Childhood white matter disorders: quantitative MR imaging and spectroscopy. Radiology 2006;241(2):510-7.

[8] Verbruggen KT, Meiners LC, Sijens PE, et al. Magnetic resonance imaging and proton magnetic resonance spectroscopy of the brain in the diagnostic evaluation of developmental delay. Eur J Paediatr Neurol 2009;13(2):181-90.

[9] Weiss U, Bacher R, Vonbank $H$, et al. Cognitive impairment: assessment with brain magnetic resonance imaging and proton magnetic resonance spectroscopy. J Clin Psychiatry 2003;64(3):235-42.

[10] Vythilingam M, Charles HC, Tupler LA, et al. Focal and lateralized subcortical abnormalities in unipolar major depressive disorder: an automated multivoxel proton magnetic resonance spectroscopy study. Biol Psychiatry 2003;54(7):744-50.

[11] Levitt JG, O'Neill J, Blanton RE, et al. Proton magnetic resonance spectroscopic imaging of the brain in childhood autism. Biol Psychiatry 2003;54(12):135566.
[12] Alkan A, Sarac K, Kutlu R, et al. Proton MR spectroscopy features of normal appearing white matter in neurofibromatosis type 1. Magn Reson Imaging 2003;21(9):1049-53.

[13] Moore GJ. Proton magnetic resonance spectroscopy in pediatric neuroradiology. Pediatr Radiol 1998;28(11):805-14.

[14] Kreis R, Ernst T, Ross BD. Development of the human brain: in vivo quantification of metabolite and water content with proton magnetic resonance spectroscopy. Magn Reson Med 1993;30(4):424-37.

[15] Yeo RA, Hill D, Campbell R, et al. Developmental instability and working memory ability in children: a magnetic resonance spectroscopy investigation. Dev Neuropsych 2000;17(2):143-59.

[16] Friedman SD, Brooks WM, Jung RE, et al. Quantitative 1H-MRS predicts outcome following traumatic brain injury. Neurology 1999;52(7):1384-91.

[17] Ford CC, Griffey RH, Matwiyoff NA, et al. Multivoxel 1H-MRS of stroke. Neurology 1992;42(7):1408-12.

[18] Majnemer A, Shevell MI. Diagnostic yield of the neurologic assessment of the developmentally delayed child. J Pediatr 1995;127(2):193-9.

[19] Scarabino T, Popolizio T, Bertolino A, et al. Proton magnetic resonance spectroscopy of the brain in pediatric patients. Eur J Radiol 1999;30(2):142-53.

[20] Barkovich AJ, Baranski K, Vigneron D, et al. Proton MR spectroscopy for the evaluation of brain injury in asphyxiated, term neonates. Am J Neuroradiol 1999;20(8):1399-405.

[21] Altinok D, Yildiz YT, Seçkin D, et al. MRI of three siblings with Sjögren-Larsson syndrome. Pediatr Radiol 1999;29(10):766-9.

[22] Nakayama M, Távora DG, Alvim TC, et al. MRI and 1HMRS findings of three patients with sjögren-larsson syndrome. Arq Neuropsiquiatr 2006;64(2B):398-401.

[23] Van Domburg PH, Willemsen MA, Rotteveel JJ, et al. Sjögren-Larsson syndrome: clinical and MRI/MRS findings in FALDH-deficient patients. Neurology 1999;52(7):1345-52.

[24] Miyanomae Y, Ochi M, Yoshioka H, et al. Cerebral MRI and spectroscopy in Sjögren-Larsson syndrome: case report. Neuroradiology 1995;37(3):225-8.

[25] Mano T, Ono J, Kaminaga T, et al. Proton MR spectroscopy of Sjögren-Larsson's syndrome. AJNR 1999;20(9):1671-3.

[26] Haltia M, Rapola J, Santavuori P. Infantile type of socalled neuronal ceroid-lipofuscinosis: histological and electron microscopic studies. Acta Neuropathol 1973;26(2):157-70.

[27] Vesa J, Hellsten E, Verkruyse LA, et al. Mutations in the palmitoyl protein thioesterase gene causing infantile neuronal ceroid lipofuscinosis. Nature 1995;376(6541):584-7.

[28] Erol I, Alehan F, Pourbagher MA, et al. Neuroimaging findings in infantile GM1 gangliosidosis. Eur J Pediatric Neurol 2006;10(56):245-8. 
[29] Stockler S, Schutz PW, Salomons GS. Cerebral creatine deficiency syndromes: clinical aspects, treatment and pathophysiology. In: Salomons GS, Wyss M. (eds). Creatine and creatine kinase in health and disease. Springer, 2007:149-6621.

[30] Dezortova M, Jiru F, Petrasek J, et al. 1H MR spectroscopy as a diagnostic tool for cerebral creatine deficiency. Magna Reson Matter Phy 2008;21(5):327-32.

[31] Wyss M, Kaddurah-Daouk R. Creatine and creatinine metabolism. Physiol Rev 2000;80(3):1107-213.

[32] Warne R, Bynevelt M, Lewis B. 1H magnetic resonance spectroscopy: a diagnostic instrument for cerebral creatine deficiency syndrome. EPOS 2012:1-12.

[33] Blau N, van Spronsen FJ, Levy HL. Phenylketonuria. Lancet 2010;376(9750):1417-27.

[34] Van Spronsen FJ, Hoeksma M, Reijngoud DJ. Brain dysfunction in phenylketonuria: is phenylalanine toxicity the only possible cause. J Inherit Metab Dis 2009;32(1):46-51.
[35] Kemp JA, Leeson PD. The glycine binding site of the NMDA receptor: five years on. Trends Pharmacol Sci 1993;14(1):20-5.

[36] Möller HE, Vermathen P, Ullrich K, et al. In-vivo NMR spectroscopy in patients with phenylketonuria: changes of cerebral phenylalanine levels under dietary treatment. Neuropediatrics 1995;26(4):199-202.

[37] Griffin JL, Lehtimäki KK, Valonen PK, et al. Assignment of $1 \mathrm{H}$ nuclear magnetic resonance visible polyunsaturated fatty acids in BT4C gliomas undergoing ganciclovir-thymidine kinase gene therapy-induced programmed cell death. Cancer Res 2003;63(12):3195-201.

[38] Martin E, Capone A, Schneider J, et al. Absence of Nacetylaspartate in the human brain: impact on neurospectroscopy? Ann Neurol 2001;49(4):518-21. 